\title{
In Focus
Spotlight on the March 18 Issue
}

\author{
Robert A. Gross, MD, PhD, FAAN \\ Editor-in-Chief, Neurology ${ }^{\circledR}$
}

\section{Sex differences in quality of life after ischemic stroke}

The authors assessed quality of life in patients with ischemic stroke or TIA at 3 and 12 months. After accounting for

sociodemographic variables, stroke severity, and disability, women had lower quality of life than men after stroke. The reasons could be decreased mobility, pain, and anxiety/depression after stroke.

See p. 922

Taurine trial in succinic semialdehyde dehydrogenase deficiency and elevated CNS GABA $\underline{\underline{\underline{\underline{A}}}}$

Taurine is an amino acid with potential neuroprotective effects based on effectiveness in an animal model and anecdotal reports in succinic semialdehyde dehydrogenase deficiency. This disorder of GABA metabolism is characterized by severe intellectual disability, verbal impairment, ataxia, and epilepsy; however, a taurine trial did not result in improvement in adaptive behavior.

See p. 940

The expanding clinical and genetic spectrum of ATP1A3related disorders

Characterization of key genetic/clinical features of alternating hemiplegia of childhood and rapid-onset dystonia-

parkinsonism as well as intermediate phenotypes widened the spectrum of these ATP1A3-related disorders. ATP1A3 mutation analysis should be considered in a patient with a mixed ataxic-dystonic movement disorder with rapid onset or recurrent episodes, asymmetry, and rostrocaudal gradient.

See p. 945

\section{On-road driving impairments in Huntington disease}

Certified driving assessment experts scored performance on 13 specific on-road driving skills in 30 persons with Huntington disease and 30 controls. Impairments on all levels of driving skill, even in mild stages of Huntington disease, suggest that monitoring of fitness to drive should be initiated in the early course of the disease.

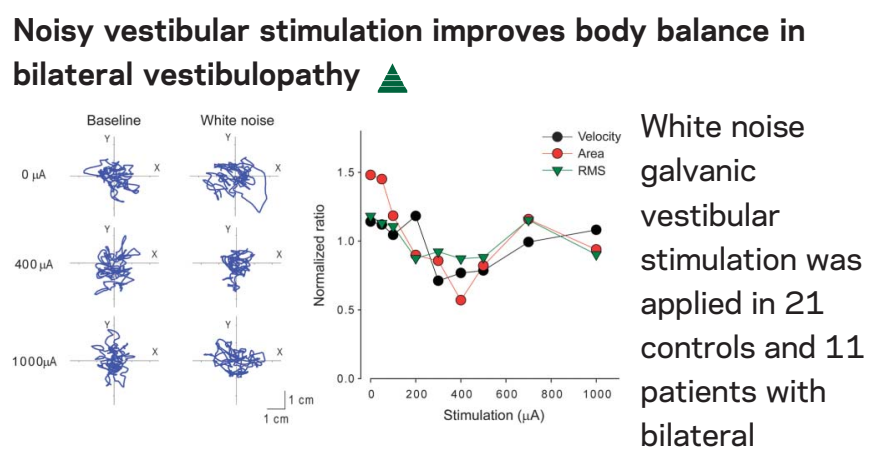

vestibular dysfunction. This study showed that noise applied to the vestibular nerve, without unilateral motor side effects, can assist postural performance in patients with vestibular dysfunction.

See p. 969

Randomized trial of IV valproate vs metoclopramide vs ketorolac for acute migraine

This study reports the efficacy and safety of 2 commonly used parenteral acute migraine medications and compares these to valproate. Of the 3 , metoclopramide was the most efficacious, while two-thirds of patients who received valproate required rescue medication. All 3 medications resulted in a low rate of sustained headache freedom.

See p. 976

\section{Daclizumab-induced adverse events in multiple organ systems in multiple sclerosis}

A retrospective chart review identified 3 multiple sclerosis patients with daclizumab-related adverse events after a mean treatment duration of 20 months, manifesting as diffuse rash and alopecia, diffuse lymphadenopathy, and breast nodules.

Daclizumab-induced adverse events can occur in various organ systems after a relatively prolonged duration of exposure and require clinical awareness.

See p. 984

NB: "Tick paralysis: A diagnosis not to miss," see p. e91. To check out other Resident \& Fellow Child Neurology articles, point your browser to Neurology.org and click on the link to the Resident \& Fellow Section. 


\title{
Neurology
}

\author{
Spotlight on the March 18 Issue \\ Robert A. Gross \\ Neurology 2014;82;907 \\ DOI 10.1212/WNL.0000000000000242
}

\section{This information is current as of March 17, 2014}

\section{Updated Information \&} Services

Permissions \& Licensing

\section{Reprints}

including high resolution figures, can be found at: http://n.neurology.org/content/82/11/907.full

Information about reproducing this article in parts (figures,tables) or in its entirety can be found online at:

http://www.neurology.org/about/about_the_journal\#permissions

Information about ordering reprints can be found online:

http://n.neurology.org/subscribers/advertise

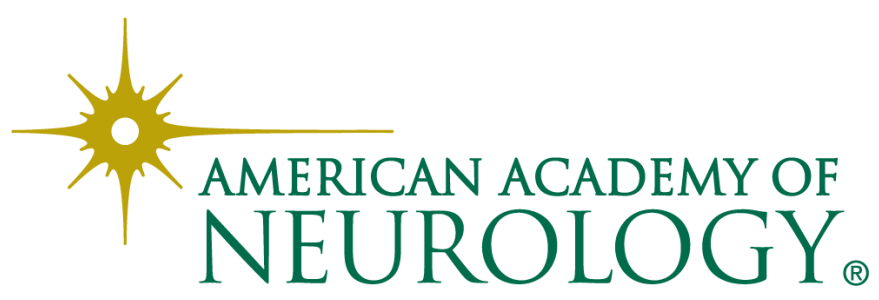

